\title{
Effectiveness of rituximab in nephrotic syndrome treatment
}

\author{
KATARZYNA POPKO ${ }^{l}$, ELŻBIETA GÓRSKA ${ }^{l}$, ELŻBIETA KUŹMA-MROCZKOWSKA ${ }^{2}$
}

'Department of Laboratory Diagnostics and Clinical Immunology of Development Age, Medical University of Warsaw, Poland ${ }^{2}$ Department of Pediatrics and Nephrology, Medical University of Warsaw, Poland

\begin{abstract}
Idiopathic nephrotic syndrome (INS) is a common chronic illness characterized by massive proteinuria and hypo-albuminemia in children. Baseline treatment is 6 month-corticotherapy. In cases of steroid resistant/dependent INS several types of treatment are used, including course of methyloprednisolone "pulses", alkylating agents, cyclosporin A, levamisole and mycophenolate mofetil. It has been suggested that children with frequently relapsing nephrotic syndrome or steroid-dependent nephrotic syndrome had a significantly longer relapse-free period if rituximab (RTX) treatment was additionally applied. We present a case of a 4.5 boy who due to steroid-sensitive, steroid-dependent nephrotic syndrome has been successfully treated with RTX. Administration of the one dose of Rituximab in the patient caused immediate decrease of CD19/CD20 positive B lymphocyte population. The depletion of $B$ cells has been observed for the next six months. With regard to the fact that RTX treatment may affect patient's immune response, comprehensive immunodiagnostic has been conducted in a course of the Therapy.
\end{abstract}

Key words: rituximab, nephrotic syndrome, CD20.

(Cent Eur J Immunol 2017; 42 (3): 313-317)

\section{Introduction}

Nephrotic syndrome is multi-faceted, kidney affecting disease with unequivocal cause. It may be a primary kidney specific disease or secondary renal manifestation of a systemic general illness. Idiopathic nephrotic syndrome (INS) is a syndrome resulting from excessive protein loss, manifesting itself through the development of oedema, proteinuria $\geq 300 \mathrm{mg} / \mathrm{dl}$ in a urine sample or $>50 \mathrm{mg} / \mathrm{kg} / \mathrm{d}$ in 24-hour urine collection or referred to as protein/creatinine ratio $\geq 2000 \mathrm{mg} / \mathrm{g}$ in a urine sample with concomitant hypoalbuminemia $\leq 2,5 \mathrm{~g} / \mathrm{dl}[1]$.

An increased permeability of the filtration membrane plays a significant role in the pathogenesis of INS. The permeability may depend on: the loss of a negative charge of the filtration membrane which impairs its selective properties; an impaired function of the subpopulations of Th1 and Th2 helper lymphocytes contributing to the production of a factor which increases the permeability of blood vessels, i.e. vascular endothelial growth factor (VEGF), vascular permeability factor (VPF) and an impaired function of B lymphocytes as demonstrated by an increased production of IL-4 and IL-13; the so called "twohit" mechanism linking the abnormal immune regulation as regards cellular and humoral response with the pathologies of podocyte structure $[2,3]$.
Idiopathic nephrotic syndrome incidence is $1-3 / 100$ $000 /$ year in children under 16 , but the relapsing character of the disease contributes to increasing the morbidity to $16 / 100000$ [1]. First-line treatment in INS includes oral glucocorticosteroids - prednizon at a dose of $2 \mathrm{mg} / \mathrm{kg} / 24$ h or $60 \mathrm{mg} / \mathrm{m}^{2} / 24 \mathrm{~h}$.

Idiopathic nephrotic syndrome classification is based on the response to implemented treatment with glucocorticosteroids. Patients are divided into steroid-sensitive, steroid-dependent and steroid-resistant. Patients who achieve remission over 8 weeks of glucocorticosteroid treatment are classified as steroid-sensitive INS patients, patients with 2 subsequent relapses during down-titration or over 14 days following glucocorticosteroid discontinuation - steroid-dependent INS, and patients not achieving remission over 8 weeks - steroid-resistant INS [1]. The disease is steroid-dependent in ca. 20-30\% and steroid-resistant in ca. $10 \%$ of patients [4]. Some patients experience a frequently relapsing form of the syndrome, i.e. with $\geq 2$ relapses of nephrotic syndrome over 6 months after initial remission or $\geq 4$ relapses over 12 months.

In order to achieve remission in patients with steroid-resistant INS and to limit the undesirable effects of chronic corticotherapy in patients with steroid-dependent INS and/or frequently relapsing INS a number of immu-

Correspondence: Katarzyna Popko, Department of Laboratory Diagnostics and Clinical Immunology of Development Age,

Medical University of Warsaw, Marszalkowska 24, 00-576 Warsaw, Poland, e-mail: katarzyna.popko@wum.edu.pl

Submitted: 20.09.2017; Accepted: 29.09.2017 
nosuppressive agents are used: cyclosporin A (CsA), cyclophosphamide, chlorambucil, mycophenolate mofetil [1].

Rituximab (RTX) is a chimeric monoclonal murine/human antibody, produced with genetic engineering methods, which is a glycosylated immunoglobulin including human IgG1 constant regions, murine light-chain and heavy-chain variable region sequences. The antibody is produced by mammalian cell suspension culture (Chinese hamster ovary) and purified with affinity chromatography and ion exchange, including specific viral inactivation and removal procedures [5]. Rituximab is one of the most commonly used therapeutic chimeric antibodies. It was initially designed and approved by FDA for the treatment of lowgrade non-Hodgkin's B cell lymphomas. After a few years of limited therapy RTX started to be used in many cases of autoimmune diseases as off-label drug. The effective depletion of B lymphocytes seemed to be a promising approach in case of autoantibodies-dependent conditions. This monoclonal antibody is able to eradicate B cells precisely without the impact on the other leucocytes populations. The Fab region of RTX is able to recognize and bind to the four amino acid sequence of CD20 molecule. There is a few possible mechanism of the elimination of B cells coated by RTX antibody. The opsonized B lymphocytes may be directly removed from the circulation by phagocytosis in the reticulo-endothelial system, they can also be killed by the NK cells through antibody-dependent cellular cytotoxicity (ADCC) [6]. The RTX antibodies attached to CD20 antigen of B cells trigger the complement activation what may lead to cells' destruction. The other possible RTX mechanism of action bases on the induction of apoptosis which is reported to act through MAP kinase activation and p38 [7, 8]. All these mechanism may act collectively or individually depending on coexisting circumstances. However it should be taken under consideration that RTX does not eradicate plasma cells responsible for antibodies production, because they do not express CD20 antigen. The effectiveness of the therapy bases on the limitation of the new B cells production and plasma cells formation $[9,10]$.

In Poland rituximab is currently registered in the treatment of non-Hodgkin lymphomas, lymphoblastic leukaemia, rheumatoid arthritis, active granulomatosis with polyangiitis and microscopic polyangiitis [5].

Rituximab has been used worldwide in the treatment of children with steroid-dependent INS for over 10 years. Initially, solitary cases were described which referred to the effective treatment of steroid-dependent frequently relapsing INS with rituximab $[10,11]$. In subsequent years, several authors published case reports concerning beneficial effects of rituximab treatment in children with steroid-dependent and/or cyclosporin-dependent INS [8, 1216]. Randomized studies also confirmed the effectiveness of rituximab in this group of patients [17].
The effect and consequences of long-term rituximab administration and the quantity of doses still remains unspecified. Ravani et al. described a group of 46 children with INS monitored for at least one year $(6.3 \pm 4.1$ year $)$ treated with calcineurin inhibitors and prednisone. They were administered from 1 to 5 rituximab infusions during observation: median -3 years (range 1-5). Oral medications were down-titrated and completely discontinued within 45 days. Rituximab was well tolerated. The probability of remission at 6 months was $48 \%$ after the first infusion and $37 \%$ after subsequent infusions. However, the probability of remission at 1 and 2 years was $20 \%$ and $10 \%$, respectively [16].

According to KDIGO (Kidney Disease Improving Global Outcomes) 2012 recommendations Rituximab may be used in steroid-dependent children who experience adverse effects or the lack of immunosuppressive treatment effects (2C) [1].

\section{Case history}

We present a case of a boy aged 4.5 who suffers from steroid-sensitive steroid-dependent nephrotic syndrome. The first episode of nephrotic syndrome occurred at 13/12 months of age, without microhaematuria. The renal function and blood pressure were normal. Tests for systemic diseases (ANA, ANCA, complement components C3 and C4) were normal. Total IgE level was increased (245 $\mathrm{kU} / \mathrm{l}$ ), specific IgE (food and inhalants test panel) was negative. The gestation, obstetric history and previous child's development were normal. The history included quick-resolving rash following the consumption of citrus fruits. Family history was positive for steroid-sensitive nephrotic syndrome in the mother in childhood. She was treated with glucocorticosteroids. Currently, the mother has no hypertension and her renal function is normal.

Our patient had 4 episodes of nephrotic syndrome within 8 months since the onset of the disease. He was only treated with glucocorticosteroids. The image obtained via renal biopsy is similar to the one of minimal change disease. Cyclosporin A was introduced because of steroid-dependence. The drug was administered at a dose of $2 \times 0.3 \mathrm{ml}$ reaching the level of $130-92 \mathrm{ng} / \mathrm{ml}$ over 1 year and 4 months. During that period there were 6 subsequent episodes of the disease. The increase in the following features of CsA toxicity were observed: gingival hyperplasia, excessive body hair, elevated levels of uric acid and reduced magnesium in biochemical tests, increasing features of glucocorticosteroid toxicity, steroid-induced obesity, knee valgosity, hypertension, glycosuria. After completing CsA treatment, Cyclophosphamide was introduced - the patient was administered $156 \mathrm{mg} / \mathrm{kg} /$ treatment. 3 subsequent episodes of nephrotic syndrome occurred during the treatment. CsA was introduced again and RTX was administered because of the occurrence of 2 subsequent 

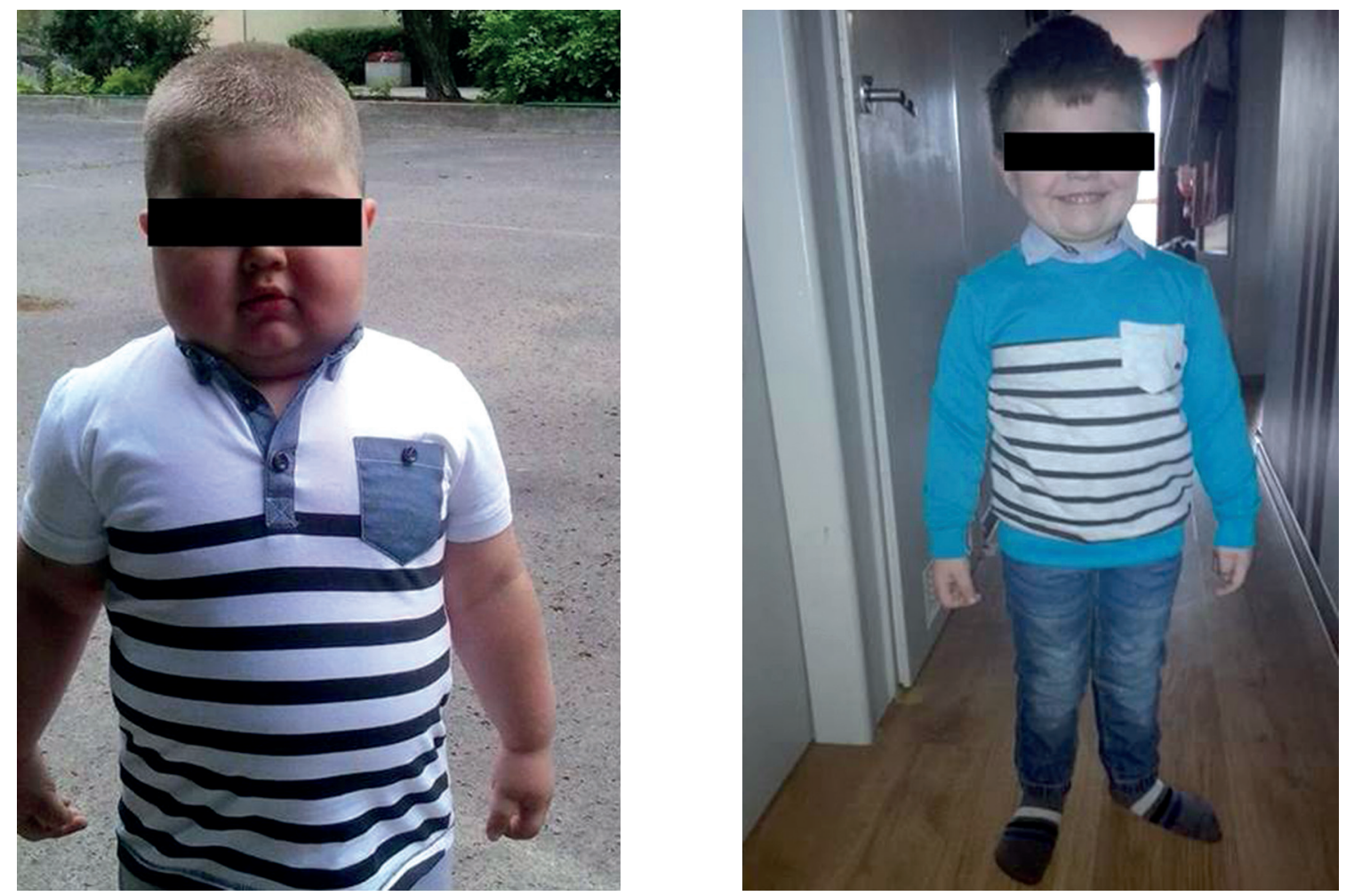

Fig. 1. Changes in physical appearance before and after rituximab treatment

Table 1. The results of immunological test in the rituximab (RTX) therapy duration

\begin{tabular}{|c|c|c|c|c|c|c|c|c|c|c|}
\hline & $\begin{array}{l}\text { Before } \\
\text { the first } \\
\text { RTX dose }\end{array}$ & $\begin{array}{c}2 \text { days } \\
\text { after the } \\
\text { first } R T X \\
\text { dose }\end{array}$ & $\begin{array}{c}2 \text { weeks } \\
\text { after the } \\
\text { first RTX } \\
\text { dose }\end{array}$ & $\begin{array}{c}1 \text { month } \\
\text { after the } \\
\text { first RTX } \\
\text { dose }\end{array}$ & $\begin{array}{l}2 \text { months } \\
\text { after the } \\
\text { first RTX } \\
\text { dose }\end{array}$ & $\begin{array}{c}4 \text { months } \\
\text { after the } \\
\text { first RTX } \\
\text { dose }\end{array}$ & $\begin{array}{l}7 \text { months } \\
\text { after the } \\
\text { first RTX } \\
\text { dose }\end{array}$ & $\begin{array}{c}\text { Before } \\
\text { the } \\
\text { second } \\
\text { RTX dose }\end{array}$ & $\begin{array}{c}1 \text { week } \\
\text { after the } \\
\text { second } \\
\text { RTX dose }\end{array}$ & $\begin{array}{l}1 \text { month } \\
\text { after the } \\
\text { second } \\
\text { RTX dose }\end{array}$ \\
\hline $\begin{array}{l}\mathrm{IgG} \mathrm{mg} / \mathrm{dl} \\
(438-1230)\end{array}$ & 433 & & 373 & 385 & 390 & & 455 & & & \\
\hline WBC & 10700 & 13580 & 6720 & 6600 & 4600 & 6340 & 9200 & 17930 & 26400 & 8600 \\
\hline CD19\%/\# & $6.41 / 114$ & $0.41 / 3.11$ & $0.1 / 1.46$ & $0.07 / 1.26$ & 0.07./0.86 & $0.98 / 13.1$ & $17.36 / 533$ & $42.32 / 776$ & $0.39 / 5.5$ & $0.04 / 1.60$ \\
\hline CD20\%/\# & $6.41 / 114$ & 0 & 0 & 0 & 0 & 1.1 & $17.3 / 531$ & $40.9 / 750$ & 0 & 0 \\
\hline Perforin $\%$ & 21.4 & 31.9 & 26.2 & 33.4 & 31.4 & 23.5 & 23.4 & 11.6 & 24.7 & \\
\hline CD4+Perf+ \% & 0.34 & 0 & 0.3 & 0.35 & 0 & 0 & 0.3 & 0 & 0 & \\
\hline CD8+Perf+ \% & 5.9 & 4.7 & 13 & 18.3 & 10.5 & 12.5 & 13.9 & 10.5 & 20.3 & \\
\hline NK\%/\# & $25.97 / 461$ & $34.08 / 262$ & $30.25 / 431$ & $23.59 / 415$ & $32.84 / 433$ & $26.64 / 282$ & $17.6 / 562$ & $11.85 / 218$ & $23.67 / 329$ & $12.32 / 478$ \\
\hline CD56+Perf+ $\%$ & 89.7 & 94.8 & 89.5 & 96.4 & 90.8 & 96.1 & 95.1 & 88.6 & 96 & \\
\hline $\mathrm{CD} 4 \% / \#$ & $26.65 / 473$ & $30.93 / 238$ & $24.82 /$ & $26.51 / 466$ & $27.15 / 358$ & $39.8 / 528$ & $32.5 / 984$ & $20.34 / 373$ & $35.06 / 488$ & $30.46 / 1182$ \\
\hline CD4\%/\# & $35.98 / 639$ & $30.31 / 233$ & $36.3 / 516$ & $43.74 / 769$ & $31.24 / 412$ & $31.29 / 415$ & $23.01 / 697$ & $21.72 / 399$ & $34.56 / 481$ & $52.81 / 2049$ \\
\hline
\end{tabular}

episodes of nephrotic syndrome (14.06.2016). Remission has been maintained for 9 months since administration. During that time CsA and glucocorticosteroids were discontinued. Blood pressure normalized and the boy lost
$5 \mathrm{~kg}$ and grew $6 \mathrm{~cm}$ taller (Fig. 1). Another episode of nephrotic syndrome occurred in March 2017. The boy was administered glucocorticosteroids at a dose of $60 \mathrm{mg} / \mathrm{m}^{2}$, and then 5 Solu-Medrol pulses. After the resolution of pro- 


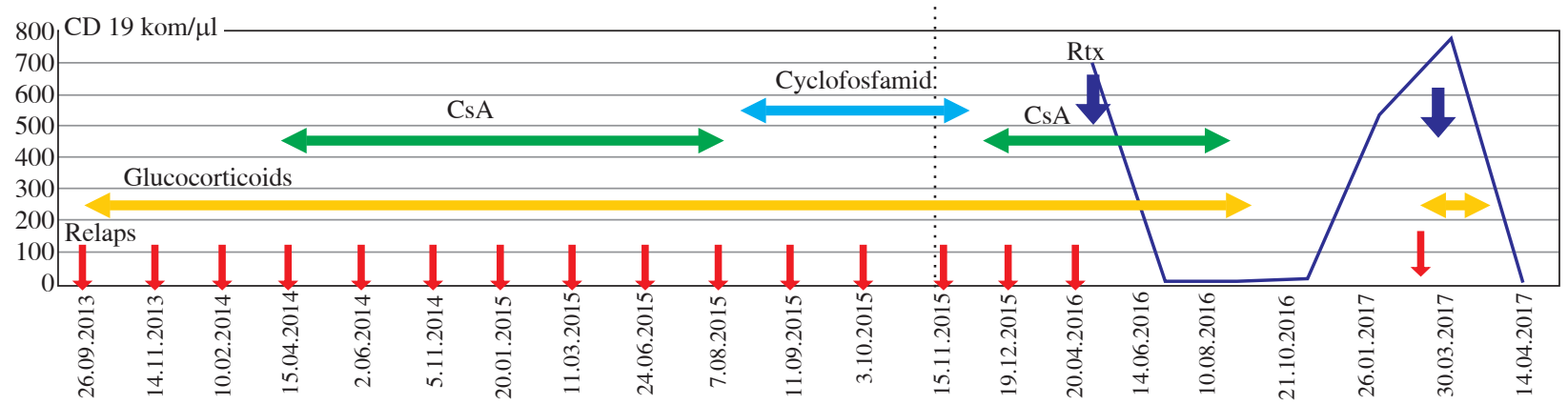

Fig. 2. The outline of the therapy including absolute numbers of CD19 lymphocytes after rituximab treatment (RTX rituximab, CsA - cyclosporin A)

teinuria the second infusion of rituximab was administered (13.04.2017). The remission has been maintained since then. The outline of the treatment is presented in Fig. 2.

With respect to the fact that RTX treatment has a great impact on the immune system and may extensively affect patient's immune response, comprehensive immunodiagnostic has been conducted in a course of the therapy. Besides the monitoring the number of CD19/CD20 B lymphocytes, T lymphocytes subpopulations CD4 and CD8 as well as NK cells have been evaluated. The percentage of NK cells as was above the referential values typical for the healthy individuals. A particular raise of NK cells has been observed shortly after RTX administration. It also seems to be interesting that the invert CD4/CD8 ratio persisted through the duration of the treatment. We didn't find any changes in the perforin expression in cytotoxic cells (Fig. 3).

Administration of the one dose of Rituximab in the patient caused immediate decrease of CD19/CD20 positive B lymphocyte population. The depletion of $\mathrm{B}$ cells has been observed for the next six months. In the sevenths month increase of CD19/CD20 lymphocytes was noticed for that reason subsequent dose of RTX was given.

Although the RTX therapy seems to be very effective in case of patients with steroid-sensitive steroid-dependent nephrotic syndrome, disease relapses are frequent, difficult to predict and impossible to avoid. It has to be also taken into consideration that complete eradication of B lymphocytes in a long term distance, may affect patient's immune response so that specific immunological tests are recommended in the RTX therapy duration.

The authors declare no conflict of interest.

\section{References}

1. KDIGO Clinical Practice Guideline for Glomerulonephritis (2012): Kid Int Suppl 2012; 2.

2. Machuca E, Esquivel EL, Antignac C. Idiopathic nephrotic syndrome in children: Genetic aspects. Niaudet P, Boyer O.
Idiopathic nephrotic syndrome in children: Clinical aspects. In: Paediatric Nephrology. Avner ED, Harmon WE, Niaudet P, et al. (eds.). Springer-Verlag Berlin, Heidelberg 2009; 643-702.

3. Pereira Wde F, Brito-Melo GE, Guimarăes FT, et al. (2014): The role of the immune system in idiopathic nephrotic syndrome: a review of clinical and experimental studies. Inflamm Res 63: 1-12.

4. Barnett HL, et al. (1981): Report of the International Study of Kidney Disease in Children. The primary nephrotic syndrome in children. Identification of patients with minimal change nephrotic syndrome from initial response to prednisone. J Pediatr 98: 561-564.

5. Rituximab - summary of product characteristics. Roche Pharma AG, Germany.

6. Cardarelli PM, Quinn M, Buckman D, et al. (2002): Binding to $\mathrm{CD} 20$ by anti-B1 antibody or $\mathrm{F}\left(\mathrm{ab}^{\prime}\right)(2)$ is sufficient for induction of apoptosis in B-cell lines. Cancer Immunol Immunother 51: 15-24.

7. Pedersen IM, Buhl AM, Klausen P, et al. (2002): The chimeric anti-CD20 antibody Rituximab induces apoptosis in B-cell chronic lymphocytic leukemia cells through a p38 mitogen activated protein-kinase-dependent mechanism. Blood 99: 1314-1319.

8. Gürcan HM, Keskin DB, Stern JN, et al. (2009): A review of the current use of rituximab in autoimmune diseases. Int Immunopharmacol 9: 10-25.

9. Randall KL (2016): Rituximab in autoimmune diseases. Aust Presc 39: 131-134.

10. Benz K, Dötsch J, Rascher W, et al. (2004): Change of the course of steroid-dependent nephrotic syndrome after rituximab therapy. Pediatr Nephrol 19: 794-797.

11. Gilbert RD, Hulse E, Rigden S (2006): Rituximab therapy for steroid-dependent minimal change nephrotic syndrome. Pediatr Nephrol 21: 1698-1700.

12. Guigonis V, Dallocchio A, Baudouin V, et al. (2008): Rituximab treatment for severe steroid- or cyclosporin-dependent nephrotic syndrome: a multicentric series of 22 cases. Pediatr Nephrol 23: 1269-1279.

13. Gulati A, Sinha A, Jordan SC, Hari P, et al. (2010): Efficacy and safety of treatment with rituximab for difficult steroid-resistant and -dependent nephrotic syndrome: multicentric report. Clin J Am Soc Nephrol 5: 2207-2212.

14. Kemper MJ, Gellermann J, Habbig S, et al. (2012): Long-term follow-up after rituximab for steroid-dependent idiopathic nephrotic syndrome. Nephrol Dial Transplant 27: 1910-1915. 
15. Iijima K, Sako M, NozuK, et al. (2014): Rituximab for childhood-onset, complicated, frequently relapsing nephrotic syndrome or steroid-dependent nephrotic syndrome: a multicentre, double-blind, randomised, placebo-controlled trial. Lancet 384: 1273-1281.

16. Ravani P, Ponticelli A, Siciliano C, et al. (2013): Rituximab is a safe and effective long-term treatment for children with steroid and calcineurin inhibitor-dependent idiopathic nephrotic syndrome. Kidney Int 84: 1025-1033.

17. Ravani P, Magnasco A, Edefonti A, et al. (2011): Shortterm effects of rituximab in children with steroid- and calcineurin-dependent nephrotic syndrome: a randomized controlled trial. Clin J Am Soc Nephrol 6: 1308-1315. 